\title{
Design lessons from the analysis of nurse journeys in a hospital ward
}

\author{
Authors: \\ Masoumeh Nazarian, PhD, University Teacher in Architecture, Loughborough University \\ Andrew D. Price, DSc, PhD, Professor of Project Management, Loughborough University \\ Peter Demian, PhD, Senior Lecturer in Construction Management, Loughborough University \\ Masoud Malekzadeh, PhD, Senior Lecturer in Architecture \& 3D Design, University of Northampton
}

Abstract

(1) Objective

The objective is to establish design strategies to help minimize nurse journeys and inform future decision-making. The impact of the ward layout was investigated through a case study ward in a multi-specialty hospital in Tehran.

(2) Background

Nurse teams have the most direct contact with ward patients. Time spent on activities not part of care provision should be minimized. Literature suggests that a significant part of nurses' time is spent moving between different places within wards, which emphasizes the importance of ward layout.

(3) Methods

The ethnographic method was adopted for observing nurses' actions based on routes that form a significant share of nurses' daily journeys. Data were collected from 42 nursing staff over 120 hours during different shifts.

This provided empirical data on the frequency of each journey which revealed meaningful patterns. Approximately 1300 room-to-room journeys were made. Conclusions were drawn about the criticality of each route.

\section{(4) Results}

There is a significant difference between the frequencies of different routes in the case study ward. The distances between origins and destinations of the most frequently used journeys must remain minimal. Awareness of less frequent routes allows for greater flexibility in ward design.

\section{(5) Conclusion}

Arrangement of ward spaces can minimize journey times. Healthcare planners and designers can explore the implications of chosen systems on walking distance and, consequently, the nursing staff productivity. For existing wards, re-arrangement of space utilization can improve staff productivity. The recommendations can be applied wherever productivity is influenced by walking distances.

\section{Keywords:}

Observation-based data analysis, hospital ward, journey frequency, design optimisation, proximity matrix 


\section{Introduction}

Healthcare environmental interventions and their impact on patient health outcomes have been the focus of a significant body of research over the last decade (Laursen et al., 2014). Many previous studies cover maintenance, refurbishment or relocation practices, where the health outcomes of patients are measured before and after each intervention. Some offer comparisons between healthcare environments and qualities which contribute to the health outcomes. A review of these studies demonstrates that healthcare environments can significantly impact the healing process and patients' wellbeing (Huisman et al., 2012). Such evidence suggests that, for example, interventions in healthcare built environments can contribute to: a 9\% reduction in the duration of patient stay in a hospital (Ulrich, 1984); a 22\% reduction in patients' feeling of pain (Lawson \& Phiri, 2003); a decline of $67 \%$ in medication errors (Hendrich, Fay \& Sorrells, 2004); $17.3 \%$ reduction in patients' fall accidents (Brandis, 1999); 70\% reduction in patient psychological distress (Lawson \& Phiri, 2003); and may even result in total eradication of hospital acquired infections (Oren, Haddad, Finkelstein \& Rowe, 2001).

There are many factors that contribute to the design of more efficient hospitals (Kazanasmaz, 2006). Supportive built environments with good internal layouts, accessibility and circulation can create an overall inviting, calming, engaging, and more hygienic and productive healthcare environment for staff, patients and their relatives. Improving productivity in hospitals is a longstanding issue. Kuhn (2000) introduced Henry Ford, founder of Ford motor company, as one of the pioneers of transferring the concept of productivity from automotive industry into healthcare. When designing a hospital for his staff, Henry Ford stated "in a normal hospital, nurses are forced to make many unnecessary steps; hence they spend more time walking around than nursing the patients" (Kuhn, 2000, p. 1) which still seems to be a challenge today. A later study showed that nurses spend close to one-third of their time walking in the unit between patient rooms, the nursing unit core and the nurses' station, which, in turn, resulted in fatigue (Joseph \& Ulrich, 2007). 
Nazarian et al. 2018, HERD

Much research has investigated the negative or positive impact of different environmental factors on nurses' work processes and the importance of enhancing these processes (Applebaum et al., 2010; Chaudhury et al., 2009; Hayhurst et al.).

One of the key physical factors of a nurse's work environment is the ward configuration and special complexities (Sagha Zadeh et al., 2012). Several studies support the significance of improving ward organization and design as well as optimizing the nurses' movement to increase the quality of nurses' time, the safe delivery of care and healthcare unit productivity (Hendrich et al., 2008; Heo et al., 2009) and substantial functional and financial efficiency (Sagha Zadeh et al., 2012). Many efforts have been made to improve the performance of medical staff by changing workspace layout. Some studies investigated the impact of the unit layout on the amount of time spent walking and demonstrated that saved walking time can be translated into more time spent on patient-care activities and interaction with family members (e.g. Shepley, 2002; Shepley \& Davies, 2003; Sturdavant, 1960; Trites, Galbraith, Sturdavant, \& Leckwart 1970, Nazarian et al., 2011), as well as improving patient satisfaction (RWJF \& IHI, 2006).

\section{Method}

Data were collected between 26th May and 20th Jun 2013. Forty-two members of staff, including head nurse, nurse, nurse assistant and ward housekeeper, participated during three different working shifts.

\section{Site and Settings}

A general hospital ward in Iran was selected because of its availability, i.e. a convenience sampling strategy. The case study ward accommodated sixteen in-patients in four double-bed rooms and eight single-bed rooms with an approximate total floor area of $440 \mathrm{~m}^{2}\left(4736.12 \mathrm{ft}^{2}\right)$. The ward usually housed patients requiring various internal surgery procedures such as: orthopedic, urology, general surgeries with open, advanced or laparoscopic methods, brain and neurosurgeries, spinal 
Nazarian et al. 2018, HERD

cord, plastic surgery, ear, nose and throat (E.N.T.) surgeries, thorax surgery, and various cardiovascular procedures.

Rooms were arranged around an ' $L$ shaped' corridor with the nurses' station positioned at the bend in the corridor to maximize views to the whole ward. Most of the single-bed rooms had a floor area of $17.5 \mathrm{~m}^{2}\left(188.37 \mathrm{ft}^{2}\right.$ ) (including en-suite sanitary facilities); double-bed rooms had a floor area of $25.5 \mathrm{~m}^{2}\left(274.48 \mathrm{ft}^{2}\right)$. The area of other spaces in the ward was measured as follows.

- The nurses' station: $12 \mathrm{~m}^{2}\left(129.17 \mathrm{ft}^{2}\right)$

- Treatment room: $25 \mathrm{~m}^{2}\left(269.10 \mathrm{ft}^{2}\right)$

- Staff room (including toilet and shower): $24.5 \mathrm{~m}^{2}\left(263.72 \mathrm{ft}^{2}\right)$

- Staff changing room: $7 \mathrm{~m}^{2}\left(75.35 \mathrm{ft}^{2}\right)$

- Hoteling storage: $3 \mathrm{~m}^{2}\left(32.29 \mathrm{ft}^{2}\right)$

- Soiled room: $1.5 \mathrm{~m}^{2}\left(16.15 \mathrm{ft}^{2}\right)$

- Cleaning utility: $0.8 \mathrm{~m}^{2}\left(8.61 \mathrm{ft}^{2}\right)$

\section{Participants}

Patient care activities were performed by three types of staff members: head nurse; nurse; and nurse assistant. Housekeepers were also responsible for the physical maintenance and cleanliness of the ward. The nursing activities of different staff types were designed based on the following shift pattern (Table 1).

Table 1: Number of ward staff per shift

\begin{tabular}{|l|l|l|l|}
\hline Shifts & \multicolumn{1}{|c|}{ 07:00-13:00 } & \multicolumn{1}{c|}{$13: 00-19: 00$} & \multicolumn{1}{c|}{ 19:00-07:00 } \\
\hline \multirow{5}{*}{ Staff } & $\begin{array}{l}\text { 1x Head /In-charge nurse } \\
\text { 3x Nurses }\end{array}$ & $\begin{array}{l}\text { 1x Head /In-charge nurse } \\
\text { 3x Nurses }\end{array}$ & $\begin{array}{l}\text { 1x Head/In-charge nurse } \\
\text { 2x Nurses } \\
\end{array}$ \\
& $\begin{array}{l}\text { 2x Nurse Assistants } \\
\text { 2x Ward Housekeeper }\end{array}$ & 2x Ward Housekeeper & 1x Nurse Assistants \\
& 2x Ward Housekeeper \\
\hline
\end{tabular}

There were no meaningful changes in the workload distribution between different days of the week, as confirmed by the staff in the interviews, due to the random nature of the health problems referred to this ward. The observed nursing staff had various duties as follows. 
- Head nurse: Head nurse or in-charge nurse in the ward was responsible for the performance of all staff and the monitoring of nurses, nurse assistants and housekeepers to ensure they met all their targets. She/he also ensured that all the patients' needs were met, and hospital's service level standards were observed by allocating resources (including nursing staff, medication, doctors and equipment) where needed. In the absence of the head-nurse, one of the most experienced nurses in the ward, previously trained to act as incharge nurse, assumed the head nurse's duties.

- Nurse: In the observed ward, the bulk of the care, especially medical and emotional care, received by the patients and their families was provided by the nurses. Furthermore, nurses played a major part in monitoring and recording patients' well-being and complementing activities of the doctors in their absence. They were also prepared to deal with different types of emergency that could occur in a ward. As part of their daily routine, nurses also made frequent journeys to other parts of the hospital outside their own ward. These journeys were normally to escort patients to and from their destinations outside the ward.

- Nurse assistant: A significant part of patients' physical care was performed by nurse assistants. These included all non-medical matters that facilitate the healing process of the patients, such as supporting personal hygiene and daily living needs. Also, transportation of the patients to and from other departments was one of the responsibilities of the nurse assistants.

- Ward housekeeper: Housekeepers were observed to be solely responsible for the upkeep of the facilities of the ward. The housekeepers' duties included cleaning and sanitization of toilets and showers, patient room equipment, nurses' station, medical equipment, corridors, escape routes, bins, cupboards and lifts. Cleaning and preparation of the patient room and bed before the arrival of a new patient was also part of their job. Although data were collected for their housekeepers' activities, these were subsequently excluded as they had no nursing responsibilities. 


\section{Data Collection}

The first phase of data collection involved observing nursing staff activities to create realistic lists of duties and tasks performed by different types of nursing staff throughout each working shift. The lists were then validated by interviewing staff members to ensure their comprehensiveness. Of the 42 staff-members who were observed, nine were interviewed. These interviews lasted an average 30 minutes. A summary of these lists is presented in Table 2.

Table 2: List of daily activities per staff type

\begin{tabular}{|c|c|c|}
\hline \begin{aligned} & \multicolumn{1}{c}{ Head Nurse } \\
& \\
& Shift handover \\
&$>$ Control and supervision \\
& of all patients \\
&$>$ Retrieval and input of \\
& medical tests \\
&$>$ Attendance to doctor \\
& during patient visits \\
&$>$ Check of doctors' orders \\
& and pursuit \\
&$>$ Notification of relevant \\
& doctor after admitting a \\
& new patient \\
&$>$ Management and \\
& supervision of nurses' \\
& activities \\
&$>$ Staff rota/shift allocation \\
&$>$ Attendance to patient \\
& complaints/buzzes \\
&$>$ Report of any faulty \\
& equipment and \\
& maintenance \end{aligned} & $\begin{aligned} & \text { Nurse } \\
&>\text { Shift handover/ Patient } \\
& \text { evaluation } \\
&> \text { Drug trolley Check } \\
&> \text { Documentation } \\
&> \text { Medication Management } \\
&> \text { Administering intravenous } \\
&(\text { IV) therapy } \\
&> \text { Wound management care } \\
&> \text { Vital signs monitoring } \\
&> \text { Communication with doctors } \\
&> \text { Follow up of doctors' orders } \\
&> \text { Education of patients/families } \\
&> \text { Emotional support } \\
&> \text { Preparation of patient for } \\
& \text { surgery } \\
&>\text { New patient admission } \\
&>\text { Escort of patient to/from } \\
& \text { theatre } \\
&>\text { Escort of patient to/from } \\
& \text { special sampling centre } \\
&>\text { Escort of patient from theatre } \\
& \text { to ward/post-operation } \\
&>\text { Response to patients' calls } \\
&>\text { Attendance to visitors' } \\
& \text { requirements } \\
&>\text { Write up of reports and } \\
& \text { records }\end{aligned}$ & $\begin{aligned} & \text { Nurse Assistant } \\
& \text { Shift handover } \\
& \text { Help to patients with } \\
& \text { personal hygiene } \\
&> \text { Help to patients with daily } \\
& \text { living needs and activities } \\
&>\text { Transportation of patients } \\
&>\text { Response to patients' calls } \\
&>\text { Documentation } \\
&>\text { Preparation of patients for } \\
& \text { surgery } \\
&>\text { Urine/blood bag check } \\
&>\text { Bed preparation } \\
&>\text { Bed linen inventory check }\end{aligned}$ \\
\hline
\end{tabular}


Nazarian et al. 2018, HERD

Based on the observations and arrangements made in the preparation phase, a strategy for data collection was developed. The aim of this strategy was to manually observe all types of staff members within a 24-hour cycle (divided in two six-hour shifts and one twelve-hour shift) and record their movements between different spaces in the ward by the researcher. This was judged to be sufficient for the observation of head nurse and nurse assistant's activities that change little in their routine from day to day. For nurses, however, whose duties are much more dependent on the types of patients to whom they are attending, the routines and even the workload could meaningfully vary from day to day. For this reason, it was deemed prudent to observe each working shift of the nurses three times to eliminate the possibility of having skewed data on their activities. There were no noteworthy variations in journey data across the nursing staff types for the duration of observation was carried out for this study. The observation comprised 120 hours direct observation of:

- 72 hours of nurse activity;

- 24 hours of head nurse activity; and

- 24 hours of nurse assistant activity.

These were distributed over two weeks of observations in a pattern to cover all shifts equally. Every effort was made to ensure that observations covered as many different participants as possible (rather than observing the same nurse in different shifts). This was to eliminate the confounding effect of an individual's personal working patterns.

As a result, Data Collection Forms in Table 3, Table 4 and Table 5 were designed and tested through a pilot study over a shift to ensure the logical flow and practicality of the data collection procedure.

This method enabled the researcher to gather four different variables of data on each journey within the ward:

- the origin of the journey;

- the destination;

- start time; and

- end time. 
Table 3: Nurse data collection sample form

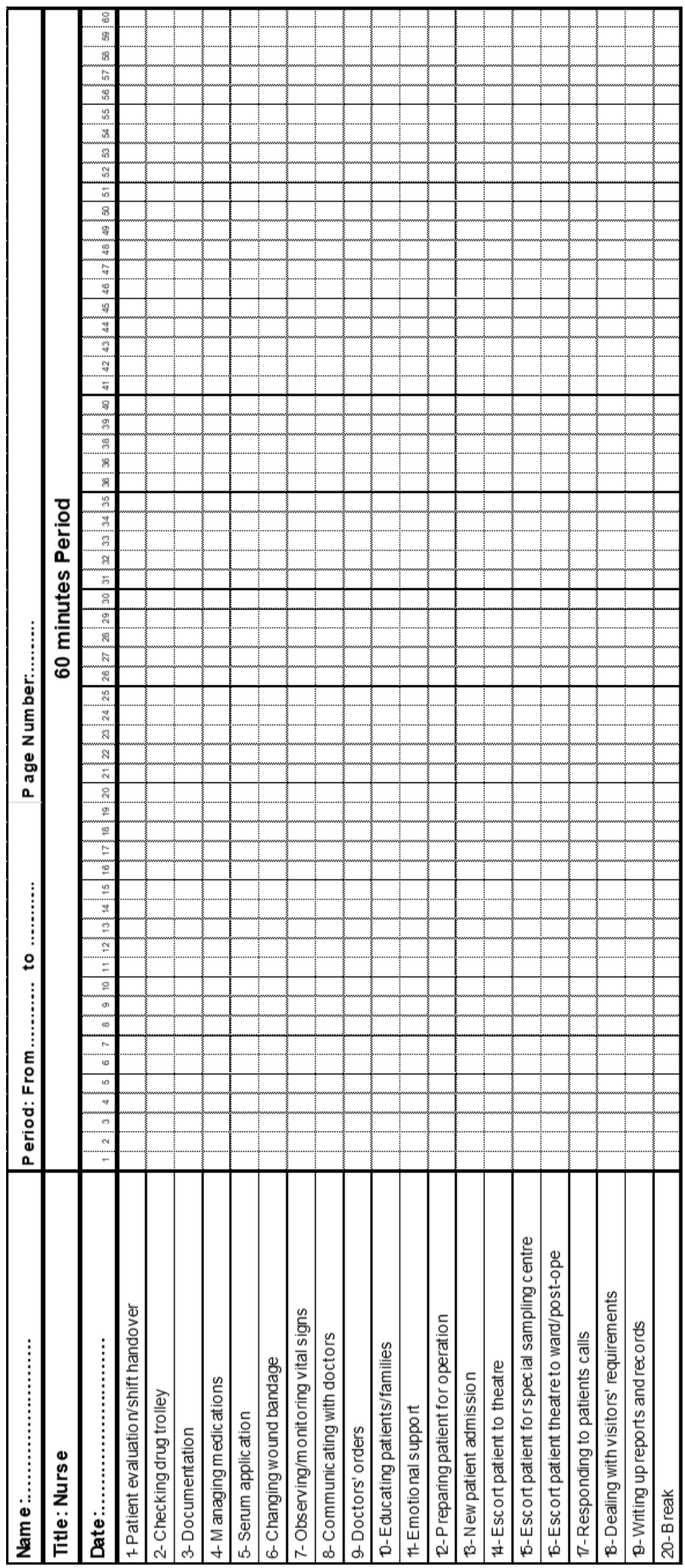


Table 4: Head Nurse data collection sample form

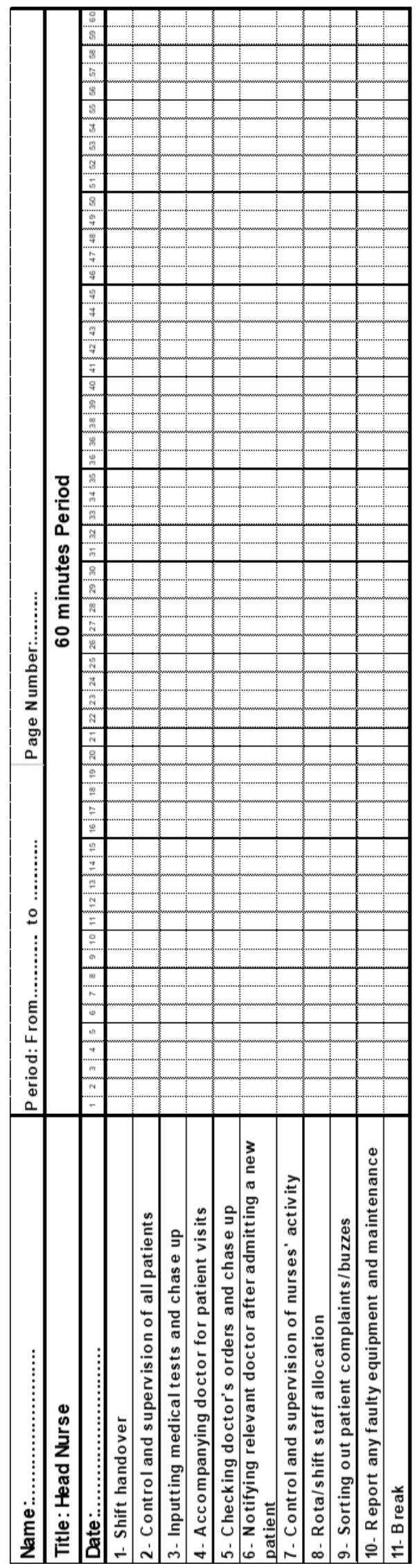


Table 5: Nurse Assistant data collection sample form

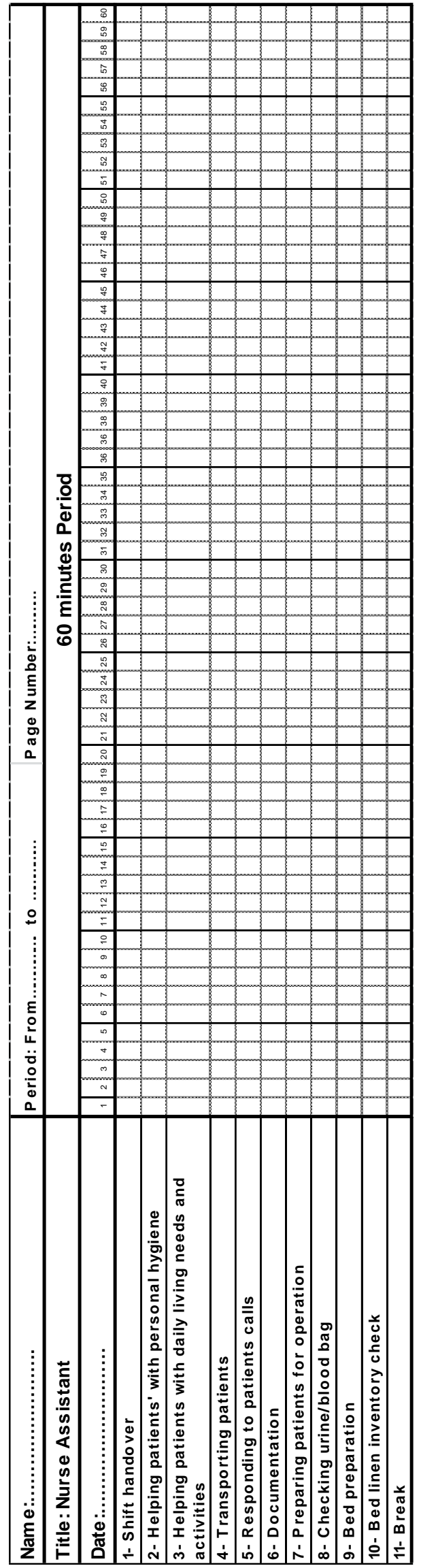


Figure 1 presents the simplified layout of the selected case study ward. This study was not concerned with the movements of the participants inside rooms as the main concern of study was the overall layout of the ward and the design of the corridors rather than the rooms themselves. Therefore, the origin/destination points of corridor journeys (numbers in Figure 1) only indicate the point of access to each of the following.

- Point 1: Nurses' station

- Point 2: Treatment room

- Point 3: Staff room

- Point 4: Soiled room

- Point 5: Used sheet bin

- Point 6: Ward entrance

- Point 7: Isolation-adaptable room

- Points 8, 9, 10,13,17, 18, 19: Single-bed rooms

- Point 11: Utility

- Points 12, 14, 15, 16: Double-bed rooms

- Point 20: Staff changing room

- Point 21: Storage

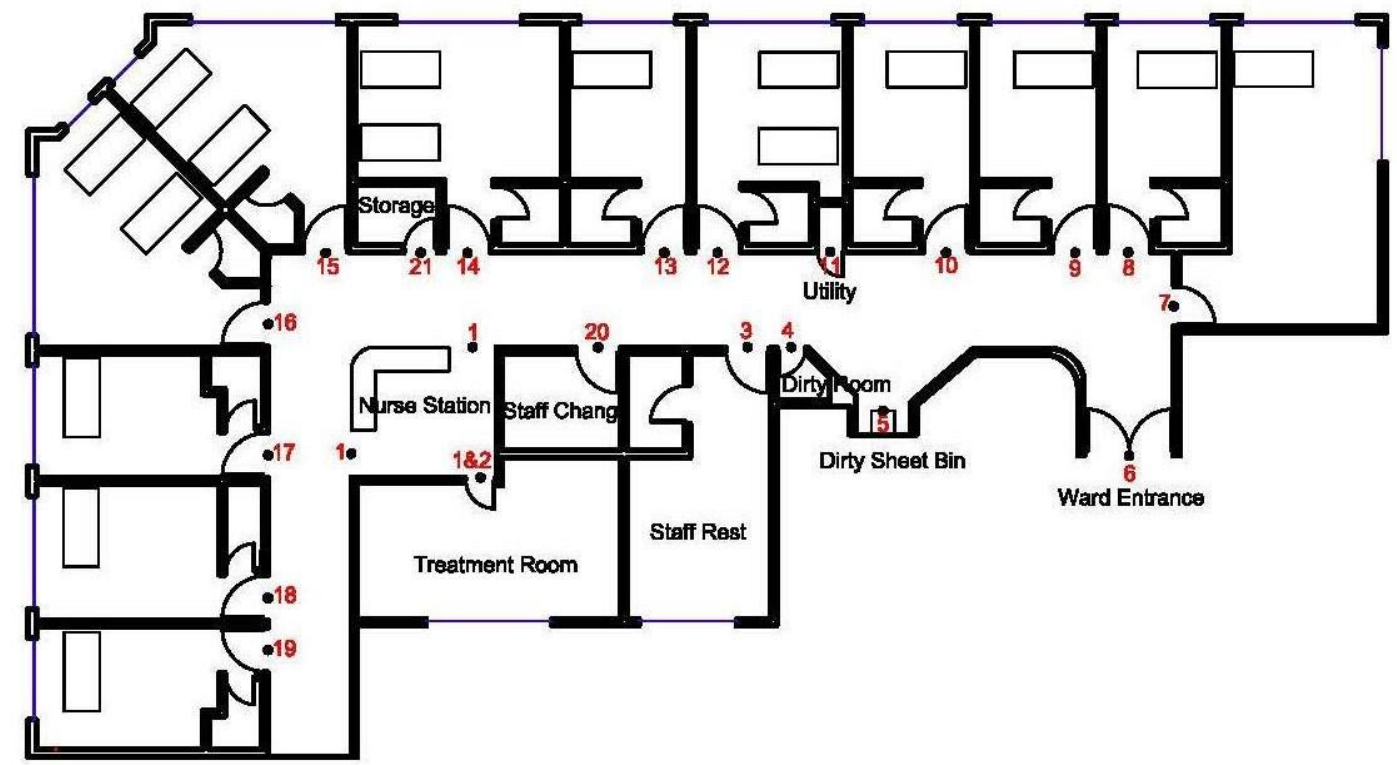

Figure 1: Origin/destination points in corridor

\section{Data Analysis}

Field observations provided empirical data on the frequency of each journey taken by nursing staff within the ward. Meaningful patterns were revealed in the data collected from the case study using a set of data analyzes. The following is a summary of these analyzes. 
A total of approximately 1300 room-to-room journeys were made by the nursing team in this ward in 24 hours. This is almost equal to one journey every 67 seconds. Several conclusions were made from the study of the journey frequency in different routes, including how critical the design of each route is, as summarized in Table 6.

Table 6: Share in daily journey frequency per level

\begin{tabular}{|c|c|c|c|c|}
\hline Frequency & Number of & Journey origin/destination & Proportion of & Average share \\
\hline 1 & 1 & $\begin{array}{c}\text { Nurse station - treatment } \\
\text { room }\end{array}$ & $8 \%$ & $8 \%$ \\
\hline 2 & 6 & $\begin{array}{c}\text { Nurse station - staff room } \\
\text { Nurse station - isolation room } \\
\text { Nurse station - 2 bed rooms }\end{array}$ & $29 \%$ & $5 \%$ \\
\hline 3 & 19 & $\begin{array}{c}\text { Nurse station - 1 bed rooms } \\
\text { Patient visit rounds }\end{array}$ & $41 \%$ & $2 \%$ \\
\hline 4 & 184 & Other & $22 \%$ & $<0.1 \%$ \\
\hline
\end{tabular}

Frequency Level 1

The most frequent nursing staff journey, the only journey taken more than 100 times during 24 hours (i.e. eight per cent all daily journeys) occurred between nurses' station and treatment room (Points 1 and 2). This agrees with the observations made during this research regarding the importance of treatment room in hosting many nursing staff activities, such as medicine preparation, in-house cleaning and sanitization, medicine and equipment stock check, and temporary storage of monitoring equipment and clean bed sheets. A good strategy in ward design is, therefore, to keep the nurses' station and treatment room adjacent to one another. This strategy had been considered in the design of the case study ward by directly connecting the two spaces through a door, thus eliminating room-to-room walking.

Frequency Level 2

The next five most frequent journeys (i.e. those taken between 50 and 100 times a day) were also to or from the nurses' station. The other ends of these journeys were Points: 3 (staff room); 7 
Nazarian et al. 2018, HERD

(isolation-adaptable room); and 12, 15 and 16 (double-bed rooms). In the case study ward, apart from acting as a staff rest area, the staff room served an additional function as non-medical administration office and ward meeting room. Subsequently, Routes 1 to 3 involved a substantial share of the team's daily journeys due to their high frequencies. This suggests reducing the distance between the two spaces to a minimum, as in the case study.

Visits from Point 1 (nurses' station) to Point 7 (isolation-adaptable room) had one of the most frequent journeys. The reason was that the room was occupied by a patient in need of special and frequent treatment. However, the importance of isolating this room from busier parts of the ward had resulted in this room being one of the furthest rooms away from the nurses' station. Visits to double-bed rooms were observed to be more frequent than those to single-bed rooms. Many tasks, especially those related to patients, needed to be repeated twice to serve both patients in these rooms. The only exception was the route to the double-bed room at Point 14; which, for most of the duration of the observations, was occupied by only one patient. It is reasonable to assume this route to be in Frequency Level 2 in normal circumstances. The routes with a Frequency Level 2 accommodated $29 \%$ of the daily journeys of the nursing staff in the ward.

Frequency Level 3

Most other journeys occurred on average more than once an hour and correspond to the routine tasks performed in patients' rooms. This pattern reflects two categories of journey: those from the nurses' station to single-bed rooms; and those performed when taking 'rounds' for activities such as doctor visit, medication, shift handover, linen change and cleaning. The latter category does not seem to be greatly dependent on design type and the nursing team would take the physical order of the rooms for such tasks regardless of the overall arrangement of the spaces. Journeys from the nurses' station to other parts of the hospital, such as pharmacy, offices, patient arrival, restaurant, etc. (i.e. Routes 1 to 6 ), are also in this range of frequency. In total, 19 routes have been categorized under this frequency level. About $41 \%$ of the daily journeys in the ward occurred in these 19 routes. 
Nazarian et al. 2018, HERD

Frequency Level 4

All other routes fall in this category of the least critical routes. The 184 routes with this frequency level are used for about $22 \%$ of the daily journeys of the staff (about $0.1 \%$ per route) some of which were observed not to be used even once by the nursing staff during the observation period. These routes should be considered as the first choice if compromises are to be made in the design of the ward in favor of more critical routes and activities.

\section{Design Recommendations for Minimizing Nurse Journey Times in Wards}

The following sections summarize the emerging recommendations for minimizing nurse journey times in wards in relation to: nurse station; treatment room; staff rooms; patient rooms; ward entrance; and a proximity matrix.

\section{Nurse stations}

The evidence from this study established that, the nurses' station was, by far, the most frequently visited space in this hospital ward. More than $50 \%$ of the nursing team's daily journeys either start from or lead to this one space. It is, therefore, important to consider the positioning of nurses' stations as the priority in the layout of a ward from the viewpoint of minimizing unnecessary walking by nursing staff.

Regardless of the overall layout of the ward, the nurses' station needs to be in a central point of the ward providing easy access to patient rooms, isolation-adaptable room, treatment room, staff room and ward entrance. However, compact designs offer an advantage over linear ones in keeping the walking distances to the end-of-the-row rooms to minimum. Inclusion of multiple smaller stations, instead of one central nurses' station is another strategy to allow easy access of the nurses to different rooms. 
Nazarian et al. 2018, HERD

\section{Treatment rooms}

More than $15 \%$ of all journeys to or from the nurses' station (and $8 \%$ of all journeys in the ward) occur between the nurses' station and treatment room. This is the most critical route in the ward from a walking distance perspective. Many nurse tasks (which start from the nurses' station) need a stop in the treatment room, for example, to pick up medicines, wound dressing sets and/or monitoring equipment from treatment room before attending patients. Most of the medical tools also need to be returned to this room for in-house cleaning. A significant part of documentation tasks was also performed here. Therefore, it is essential to keep the distance between this room and the nurses' station to minimum or eliminate it (by providing direct access between two spaces without the need of going through a corridor) to insure prevention of any extra walking for the nursing staff.

\section{Staff rooms}

The staff room had functions covering a broader range than the name suggests. Normally, ward staff visit the staff room only to take their breaks, have some quiet time, eat a sandwich, have a friendly chat or have a drink. However, the staff room also played the role of the ward 'office' hosting non-medical administrative tasks of the staff, especially the head nurse. This, although not unprecedented (according to the expert interviews during the case study), is not a necessary part of staff room's functions. Therefore, the bias of the data in over-estimating the importance of the journeys to and from this space (with nearly $8 \%$ of all journeys in the ward) should be considered when these data are used to inform design guidelines. In general, if a staff room assumes extra functions as an administration office, it needs to be near of the nurses' station and treatment room.

\section{Patient Rooms}

In addition to maximum accessibility and visibility from the nurses' station, the arrangement of patient rooms also needs to facilitate making 'rounds' (performing tasks that need to be repeated in all patient rooms one after another). For this reason, it is recommended that patient 
Nazarian et al. 2018, HERD

rooms are kept next to each other in a way that all of them can be accessed in one round trip from the center of the ward (i.e. the nurses' station). Placing patient rooms in separate wings in a ward or designing other spaces in between of a row of patient rooms, which adds un-necessary distance between the doors to two consecutive patient rooms, are design strategies that should be avoided if possible.

\section{Ward entrance}

Apart from movements between different rooms inside a ward, all other daily corridor walks of the ward staff crossed the ward entrance. The journeys to or from this point in daily nursing staff's journeys was slightly greater than $3 \%$ of the total. Journeys are to places outside the ward can from a large part of daily walking activities as the distances are much greater than those of internal journeys. The greatest part of these journeys, however, occurs outside the ward and is, therefore, out of the scope of this study.

As far as this study is concerned, the most important space in relation to ward entrance is the nurses' station. This means that the nurses' station should be kept close to the ward entrance. Further to minimizing the walking distance between the two spaces, this strategy also insures that staff in the nurses' station have constant visual control over the entrance. This is a quality that was recommended by the nurses and architects during expert interviews. However, the centrality of the nurses' station (as stated earlier) is of a greater importance and should overrule its proximity to the entrance when both qualities cannot be satisfied in a design.

\section{Proximity matrix}

To summarize the above guidelines, the suggested proximities of different spaces in a ward are presented in form of a matrix (Table 7). In this matrix, the strongest proximity need is coded as 1 (e.g. the nurses' station to treatment room) and the least important ones as 5 (e.g. staff room to service \& utility). The spectrum between these two extremes expresses how important it is for the designer to keep a pair of ward spaces close to each other. It is essential to note that this matrix only 
informs the minimization of the nursing team's walking distances. Other factors that may affect the positioning of a ward's different rooms and spaces should not to be overly compromised by this one factor. Also, the walking distances of other people in a ward, including non-nursing staff, patients and visitors, should be considered in the final design of the ward. It should also be noted that the space names in this matrix reflect a set of specific functions as defined by the case study. These functions may have different definitions in other cases.

Table 7: Ward spaces proximity matrix (Number 1 representing the first priority for minimising distance)

\begin{tabular}{|c|c|c|c|c|c|c|c|c|}
\hline & $\begin{array}{c}\text { Service \& } \\
\text { Utility }\end{array}$ & $\begin{array}{c}\text { Ward } \\
\text { Entrance }\end{array}$ & $\begin{array}{c}\text { Single- } \\
\text { bed Room }\end{array}$ & \begin{tabular}{|c|} 
Isolation- \\
adaptable \\
Room
\end{tabular} & $\begin{array}{c}\text { Double- } \\
\text { bed Room }\end{array}$ & $\begin{array}{r}\text { Staff } \\
\text { Room }\end{array}$ & $\left|\begin{array}{c}\text { Treatment } \\
\text { Room }\end{array}\right|$ & $\begin{array}{l}\text { Nurse } \\
\text { Station }\end{array}$ \\
\hline $\begin{array}{l}\text { Nurse } \\
\text { Station }\end{array}$ & 4 & 3 & 3 & 2 & 2 & 2 & 1 & - \\
\hline $\begin{array}{c}\text { Treatment } \\
\text { Room }\end{array}$ & 5 & 3 & 3 & 2 & 2 & 4 & - & \\
\hline $\begin{array}{l}\text { Staff } \\
\text { Room }\end{array}$ & 5 & 5 & 5 & 5 & 4 & - & & \\
\hline $\begin{array}{c}\text { Double- } \\
\text { bed Room }\end{array}$ & 4 & 4 & 3 & 3 & 3 & & & \\
\hline \begin{tabular}{|c|} 
Isolation- \\
adaptable \\
Room \\
\end{tabular} & 5 & 4 & 3 & - & & & & \\
\hline $\begin{array}{c}\text { Single- } \\
\text { bed Room }\end{array}$ & 4 & 4 & 3 & & & & & \\
\hline $\begin{array}{c}\text { Ward } \\
\text { Entrance }\end{array}$ & 5 & - & & & & & & \\
\hline $\begin{array}{c}\text { Service \& } \\
\text { Utility }\end{array}$ & 5 & & & & & & & \\
\hline
\end{tabular}

\section{Discussion of Results}

Data on journeys made by staff within a workplace should be an important part of determining the optimum proximity of different spaces within the workplace and selecting the most efficient design layout from several options. Methods such as the one presented in this paper can be utilized for maximizing reliability and comprehensibility of such data without much reliance on the technical expertise of the observer or the sophistication of the equipment used. 
Nazarian et al. 2018, HERD

Careful preparations are needed for data collection to ensure comprehensiveness of the data and to minimize data impairment. The example presented in this paper explains such preparations as well as the processes of data collection, data cleansing and data analyzes.

\section{Conclusions, Recommendations and Limitations}

\section{Conclusion}

This paper provides an example of how the data gathered and analyzed from an existing working ward can inform decisions for future designs. This was done through the formulation of a set of design guidelines from the research findings. These guidelines include suggestions on the location of nurse stations, treatment rooms, staff rooms, patient rooms, ward entrance and a proximity matrix of all spaces in a hospital ward. These suggestions are based on the dynamics and needs of the observed setting of the case study, and any potential generalization of these suggestions should be carried out with careful consideration of similarities and differences with the studied case.

\section{Recommendations}

The evidence from existing working patterns of the nursing staff and their room-to-room movements should form the basis of floorplan layouts in any future design (and redesign) projects.

In the design of new-build hospitals, the planned staff working patterns are based on the routines of other clinical, nursing and care teams in similar hospitals. Such assumptions may turn out not to be an exact representation of the actual working patterns of the staff after the occupation of the newly-built hospital, therefore, not delivering the expectations of the designers, for example as to the design's enabling of effective staff journeys are. In contrast, nursing teams in existing hospitals that are planning to undergo a spatial reconfiguration or refurbishment have full knowledge of their current working patterns. It is essential that these patterns should be observed, analyzed and validated with the staff before any decision on the new format of the hospital is made. 


\section{Hospital designs should accommodate potential future changes in working patterns}

Many factors, such as new technologies, techniques, services and policies may result in a shift in working patterns. Designing hospitals based on the current working patterns of the staff may have an inherent risk of a decline in the healthcare environment's effectiveness and efficiency if working patterns change. Designs that provide a valid solution for current needs of a hospital should be sufficiently resilient and flexible to accommodate the future needs without imposing unnecessary cost and effort or disruption to service. They should allow spatial rearrangement of the hospital spaces when changes in working patterns occur.

\section{Limitations}

The data collected were from a specific context (a general hospital in Iran) and the findings might not be directly generalizable to other locations, types of hospitals or healthcare systems.

\section{Funding}

This research was funded by Loughborough University's EPSRC Health and Care Infrastructure Research and Innovation Centre core [grant number EP/D039614/1 and EP/1029788/1].

\section{References}

Applebaum, D. Fowler, S., Fiedler, N., Osinubi, O., Robson, M. (2010). The Impact of Environmental Factors on Nursing Stress, Job Satisfaction, and Turnover Intention, The Journal of Nursing Administration, 40(7/8):323-328.

Brandis, S. (1999). A collaborative occupational therapy and nursing approach to falls prevention in hospital inpatients. Journal of Quality in Clinical Practice, 19(4), 215-221.

Chaudhury, H., Mahmood, A., Valente, M. (2009) The Effect of Environmental Design on Reducing Nursing Errors and Increasing Efficiency in Acute Care Settings, Environment and Behaviour Journal, 41(6):755-786.

Hayhurst, A., Saylor, C., Stuenkel, D. (2005) Work Environmental Factors and Retention of Nurses, Journal of Nursing Care Quality, 20(3):283-288. 
Hendrich, A. L., Chow, M. P., Skierczynski, B. A., \& Lu, Z. (2008). A 36-Hospital Time and Motion Study: How Do Medical-Surgical Nurses Spend Their Time? The Permanente journal, 12(3):25-34.

Hendrich, A. L., Fay, J., \& Sorrells, A. K. (2004). Effects of acuity-adaptable rooms on flow of patients and delivery of care. American Journal of Critical Care, 13(1), 35-45.

Heo, Y., Choudhary, R., Bafna, S., Hendrich, A., Chow, MP. (2009). A modelling approach for estimating the impact of spatial configuration on nurses' movement. Proceedings of the 7th International Space Syntax, Sweden, Stockholm.

Huisman, E. R. C. M., Morales, E., Hoof, J. \& van, Korta, H. S. M. (2012). Healing environment: A review of the impact of physical environmental factors on users. Building and Environment, December, 58: 70-80.

Joseph, A., \& Ulrich, R. (2007). Sound control for improved outcomes in healthcare settings. USA: The Center for Health Design.

Kazanasmaz, Z. T. (2006). Design efficiency in hospital architecture. Proceedings of First International CIB Endorsed Metu Graduate Conference, Ankara, Turkey.

Kuhn, C. (2000). ENT-Clinic, LKH Graz - From intelligent hardware to networked infrastructure. Retrieved from http://www.e-architect.co.uk/austria/ent_clinic_graz.htm Laursen, J., Danielsen, A. \& Rosenberg, J. (2014). Effects of environmental design on patient outcome: a systematic review. Health Environments Research \& Design Journal, 7(4):108-19.

Lawson, B., \& Phiri, M. (2003). The architectural healthcare environment and its effect on patient health outcomes. UK: NHS Estates.

Nazarian, M., Price, A. D. F., \& Demian, P. (2011). A review of different approaches to access and people circulation within health-care facilities and the application of modelling, simulation and visualization. Proceedings of CIB-W096 Conference 2011, 219-231.

Oren, I., Haddad, N., Finkelstein, R., \& Rowe, J. M. (2001). Invasive pulmonary aspergillosis in neutropenic patients during hospital construction: Before and after chemoprophylaxis and institution of HEPA filters. American Journal of Hematology, 66(4), 257-262.

Robert Wood Johnson Foundation \& Institute for Healthcare Improvement. (2006). A new Era in Nursing: Transforming Care at the Bedside. Retrieved from https://www.rwjf.org/content/dam/files/legacy-files/article-files/2/TCABBrochure041007.pdf

Sagha Zadeh, R., Shepley, M. M., \& Waggener, L. T. (2012). Rethinking efficiency in acute care nursing units: Analyzing nursing unit layouts for improved spatial flow. Health Environments Research \& Design Journal, 6(1), 39-65. 
Nazarian et al. 2018, HERD

Shepley, M. M. (2002). Predesign and post-occupancy analysis of staff behaviour in a neonatal intensive care unit. Children's Health Care, 31(3), 237-253.

Shepley, M., \& Davies, K. (2003). Nursing unit configuration and its relationship to noise and nurse walking behaviour: an AIDS/HIV unit case study. AIA Academy Journal, 6, 12-14.

Sturdavant, M. (1960). Intensive nursing service in circular and rectangular units. Hospitals, $34,46-71$.

Trites, D. K., Galbraith, F. D., Sturdavant, M., \& Leckwart, J. F. (1970). Influence of nursingunit design on the activities and subjective feelings of nursing personnel. Environment and Behavior, 2(3), 303-334.

Ulrich, R. S. (1984). View through a window may influence recovery from surgery. Science, $224,420-421$. 